03

\title{
Импульсная активация вскипания перегретой жидкости лазерным излучением
}

\author{
(С) А.Л. Гурашкин, А.А. Старостин, П.В. Скрипов \\ Институт теплофизики УрО РАН, Екатеринбург, Россия \\ T E-mail: pavel-skripov@bk.ru
}

Поступило в Редакцию 13 февраля 2020 г.

В окончательной редакции 27 марта 2020 г.

Принято к публикации 27 марта 2020 г.

\begin{abstract}
На примере н-пентана, перегретого на $81{ }^{\circ} \mathrm{C}$ относительно температуры равновесия жидкость-пар, показана возможность локальной активации вскипания жидкости лазерным импульсом на торце одномодового световода. Обнаружен порог активации по интенсивности излучения на торце световода. Его значение зависит от состояния торца световода, а процессы вскипания, вероятно, развиваются на границе раздела сред. Как и при случайном процессе вскипания, при активации наблюдается ступенчатое распространяющееся изменение показателя преломления жидкости. Сделан вывод об однотипности регистрируемых процессов при случайном и активированном вскипании н-пентана.
\end{abstract}

Ключевые слова: перегретая жидкость, пузырьковая камера, световод, лазерный импульс, вскипание.

DOI: 10.21883/PJTF.2020.12.49529.18245

Известно, что инициировать вскипание могут космические и радиоактивные частицы, электромагнитное излучение, акустические волны, гидродинамические явления $[1,2]$. Принято считать, что такие внешние воздействия снижают активационный барьер и облегчают вскипание жидкости при сохранении случайного характера начала процесса. В частности, проводятся исследования с воздействием интенсивного лазерного излучения [3-6]. Задача состоит в создании управляемого центра вскипания для детерминированных и повторяемых измерений характеристик быстрых процессов, свойственных начальной стадии вскипания. С учетом методологии наблюдения за перегретой жидкостью [7] наибольшие возможности в этом плане предоставляет миниатюрная пузырьковая камера.

Отправным пунктом постановки данной задачи послужило обнаружение быстрого процесса ступенчатого изменения показателя преломления жидкости, сопровождающего начальную стадию ее спонтанного вскипания от случайного локального возмущения (флуктуации) [8]. Результат получен с помощью миниатюрных оптоволоконных датчиков изменения показателя преломления жидкости, введенных в капилляр пузырьковой камеры [7-9]. Наблюдаемый процесс происходит однократно непосредственно перед регистрацией первого пузырька на кадрах скоростной видеосъемки.

Дальнейшее развитие исследований основано на предположении о возможности локальной активации обнаруженного явления как инструмента исследования источника его происхождения. Активацию источника можно осуществить воздействием коротких лазерных импульсов на предварительно перегретую жидкость через одномодовые световоды оптоволоконных датчиков с диаметром световодной жилы $10 \mu \mathrm{m}$. Малый размер из- лучающей площадки позволяет относительно простыми средствами обеспечить высокие значения интенсивности излучения на выходном торце световода в жидкости. Воспроизведение наблюдаемых явлений при активации позволит исследовать развитие быстрых процессов, сопровождающих вскипание жидкостей, и выделить существенные факторы, влияющие на зарождение паровой фазы в хорошо контролируемых условиях миниатюрной пузырьковой камеры.

Первоначальные опыты показали перспективность выбранного направления. Применена прежняя установка с двумя световодами в ячейке с перегретой (путем сброса давления) жидкостью [7,9]. Расстояние между торцами световодов $13.5 \mathrm{~mm}$. Первому световоду отводилась активирующая роль. К нему присоединялся источник мощных лазерных импульсов. Второй световод был контрольным с маломощным источником непрерывного зондирующего излучения. Оба канала содержали оптоволоконные делители для измерения величины отраженного излучения от торцов волокон на быстродействующих фотоприемниках $[8,9]$. Интенсивность отраженного излучения изменялась от долей процента в сплошной жидкости до единиц процентов при осушении торца световода. Сигнал, отраженный от жидкой фазы, отслеживался в интервале значений от 0 до $3 \mathrm{~V}$. Сигнал от паровой фазы перегружал фотоприемник и имел ограничение сверху, равное $3 \mathrm{~V}$.

Опыты проводились с источником активирующего излучения на длине волны $980 \mathrm{~nm}$ с выходной мощностью около $0.2 \mathrm{~W}$. Источник был сконструирован на основе современных мощных лазерных диодов и имел выход в одномодовое волокно. Для создания коротких импульсов тока накачки применялся специализированный драйвер с переходным временем менее $10 \mathrm{~ns}$. Таким образом, мак- 


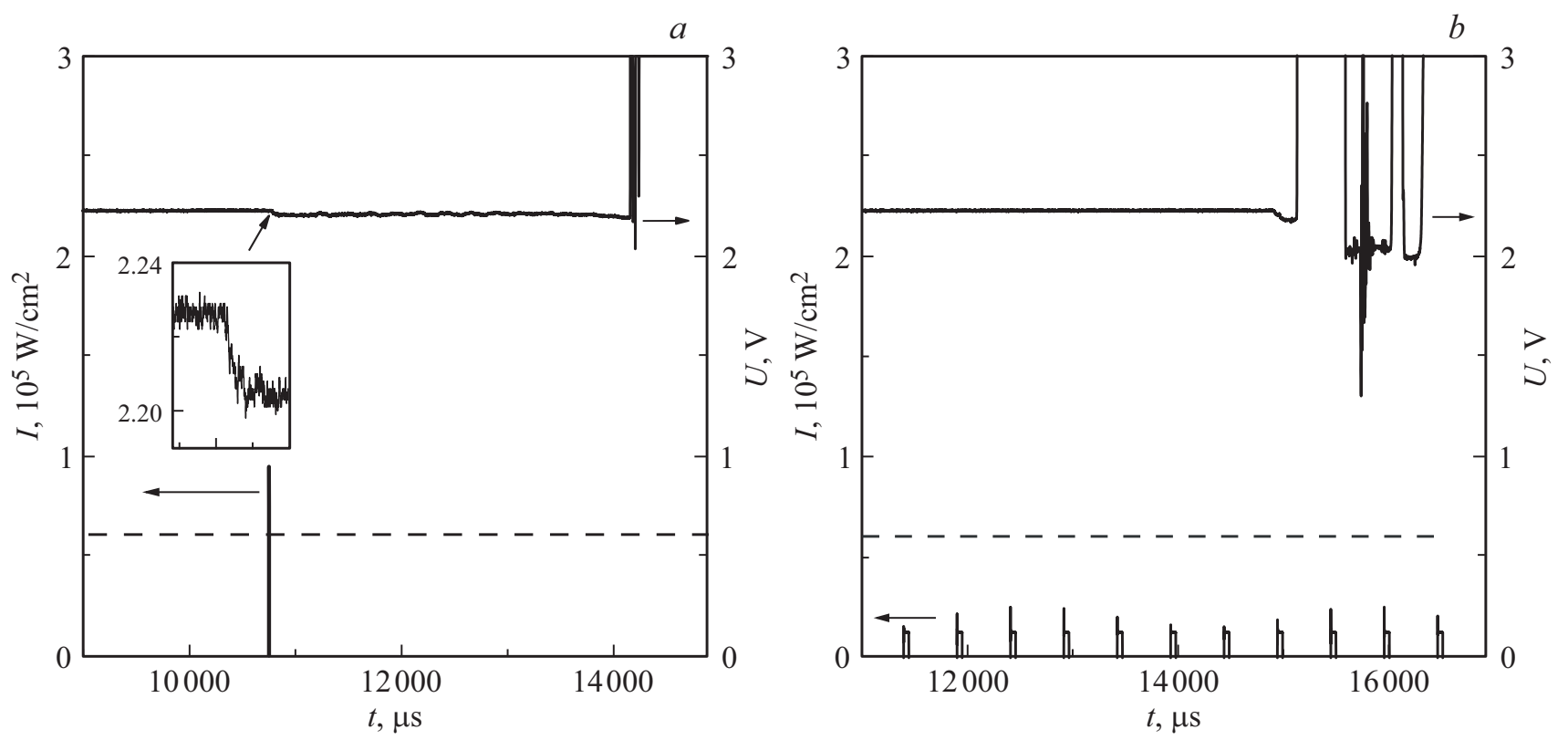

Рис. 1. Вынужденное $(a)$ и спонтанное $(b)$ вскипание перегретого н-пентана при подаче импульсов выше $(a)$ и ниже $(b)$ порога активации $0.6 \cdot 10^{5} \mathrm{~W} / \mathrm{cm}^{2}$ (штриховая линия). На вставке показано ступенчатое изменение сигнала на контрольном световоде после активирующего импульса на первом световоде.

симальная средняя интенсивность излучения на выходе одномодового световода с площади около $10^{-6} \mathrm{~cm}^{2}$ достигала $2 \cdot 10^{5} \mathrm{~W} / \mathrm{cm}^{2}$. Длительность импульсов изменялась в пределах $0.1-50 \mu \mathrm{s}$, что соответствовало изменению энергии импульсов от 0.02 до $10 \mu \mathrm{J}$ при максимальной мощности. Дополнительно была осуществлена возможность регулирования тока накачки лазерных диодов и соответственно выходной интенсивности излучения. Мощность зондирующего излучения на контрольном световоде составляла примерно $1 \mathrm{~mW}$ и поступала от маломощного лазерного диода с длиной волны $1550 \mathrm{~nm}$. Регистрация сигналов отраженного излучения с торцов активирующего и контрольного световодов проводилась быстродействующей фотоприемной и записывающей аппаратурой [7,9]. Суммарная электронно-оптическая задержка распространения сигналов не превышала $0.1 \mu \mathrm{s}$.

Изменения интенсивности отраженного излучения связаны либо с изменением интенсивности источника излучения (активирующего или зондирующего), либо с изменением показателя преломления жидкости на торце световода. Поэтому на активирующем канале регистрировался короткий импульс активации, а на контрольном канале с непрерывным источником излучения - относительные изменения отраженного зондирующего излучения, соответствующие изменениям показателя преломления жидкости во времени. Результаты записывались быстродействующим цифровым регистратором с микросекундным разрешением. Основной ряд опытов проведен в н-пентане при температуре $117^{\circ} \mathrm{C}$ и атмосферном давлении, т. е. относительно далеко от значения температуры достижимого перегрева (около $140^{\circ} \mathrm{C}$ ) и равновесия жидкость-пар $\left(36.1^{\circ} \mathrm{C}\right)$ при заданном давлении. Систе- матическое изменение интенсивности и длительности активирующих импульсов выявило наличие эффекта активации только на одном из двух световодов. Эффект имеет пороговый характер по интенсивности импульсов излучения и не зависит от длительности импульсов в пределах 0.1-50 $\mathrm{s}$. Вероятно, развитие процессов локального разрушения перегретой жидкости под действием импульса излучения происходит в пограничном слое на границе раздела сред. В этом случае пороговое значение интенсивности может определяться величиной адгезии жидкости к поверхности торца световода.

На рис. 1 приведен характерный вид сигналов с активирующего (внизу) и контрольного (вверху) оптоволоконных датчиков. Активация процесса вскипания н-пентана наблюдалась при подаче импульса с интенсивностью $\sim 10^{5} \mathrm{~W} / \mathrm{cm}^{2}$, превышающей порог активации (рис. 1,a). По аналогии со случайным процессом [7-9] при активации наблюдается ступенчатое изменение показателя преломления жидкости, сопровождающее вскипание. При воздействии пачки импульсов различной длительности с интенсивностью менее $0.6 \cdot 10^{5} \mathrm{~W} / \mathrm{cm}^{2}$ (рис. $1, b)$ вскипание происходило случайным образом, как и при отсутствии импульсов. Порог активации в условиях опыта определен на уровне $0.6 \cdot 10^{5} \mathrm{~W} / \mathrm{cm}^{2}$.

На рис. 2, а демонстрируется подобие результатов воздействия короткого $(1 \mu \mathrm{s})$ и длинного $(50 \mu \mathrm{s})$ импульсов активирующего излучения, вызывающих идентичные изменения сигнала на контрольном световоде. Ступенчатое изменение сигнала на контрольном световоде происходит синхронно с передним фронтом активирующего импульса через $\sim 35 \mu$ s. Рис. $2, b$ демонстрирует факт постоянства задержки „ступеньки“ на втором светово- 

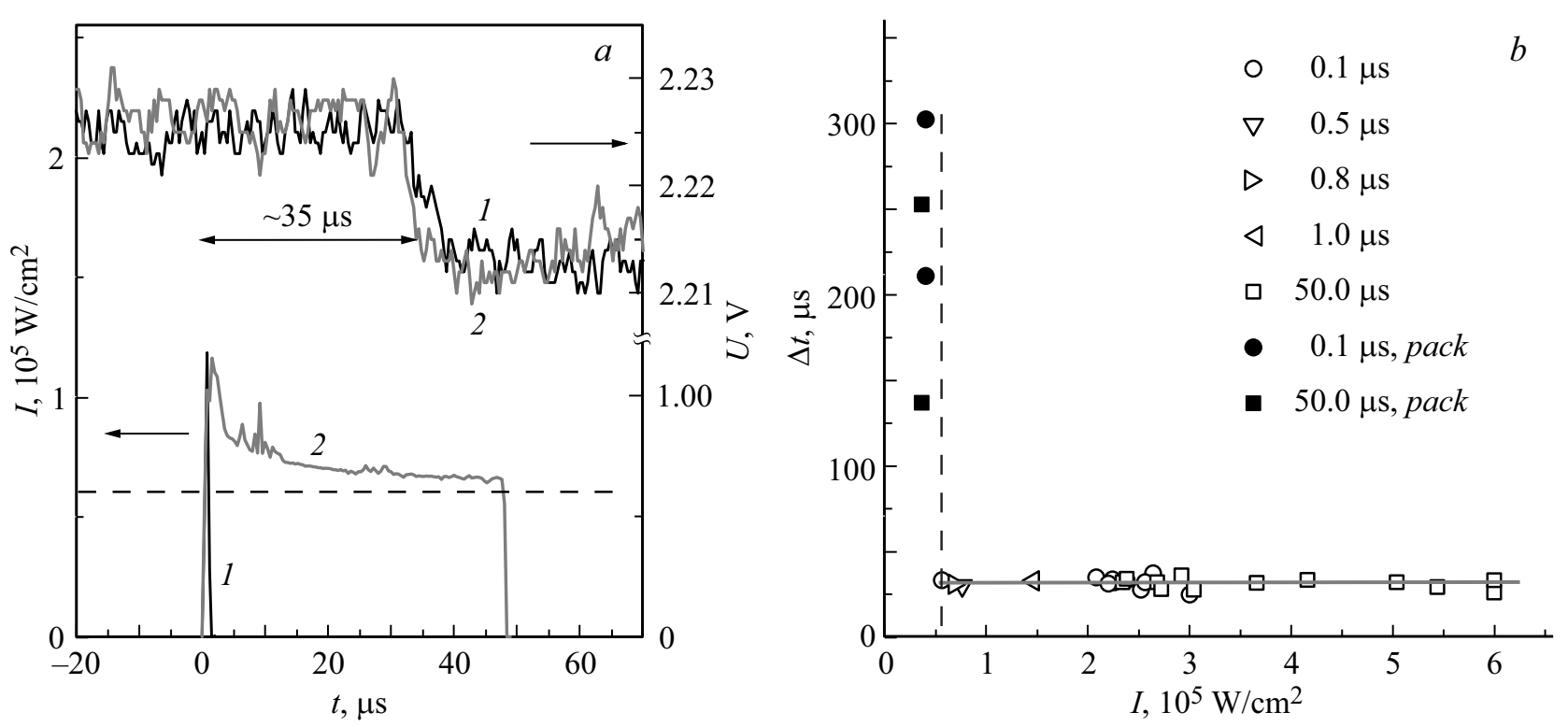

Рис. 2. $a-$ синхронное изменение сигнала на втором световоде (вверху) относительно фронта лазерного импульса (внизу, $1-1 \mu \mathrm{s}, 2-50 \mu \mathrm{s})$ с интенсивностью выше порога активации $0.6 \cdot 10^{5} \mathrm{~W} / \mathrm{cm}^{2}$ (штриховая линия). $b-$ постоянство задержки ступенчатого сигнала при превышении порога активации, pack - воздействие пачки импульсов. Для импульсов с интенсивностью ниже порога активации задержка имеет случайное значение, характерное для спонтанного вскипания [9].

де при интенсивности импульсов различной длительности, превышающей порог активации вынужденного вскипания. Ниже порога активации наблюдается переход к случайному значению задержки, соответствующей спонтанному вскипанию, независимо от длительности импульсов в интервале $0.1-50 \mu \mathrm{s}$. Можно предположить, что импульс излучения с интенсивностью выше $0.6 \cdot 10^{5} \mathrm{~W} / \mathrm{cm}^{2}$ активирует вынужденное вскипание жидкости за интервал времени, меньший $0.1 \mu \mathrm{s}$.

Таким образом, активация процесса вскипания лазерным излучением с торца световода действительно осуществима. Она происходит за время менее $0.1 \mu \mathrm{s}$, а ключевым фактором ее осуществления служит интенсивность излучения. Наблюдаемая зависимость эффекта активации от интенсивности импульса излучения при независимости от длительности позволяет предположить механическое действие давления излучения на пограничный слой жидкости. Локальный центр активации процесса вскипания получен импульсным излучением на торце одномодового световода с характерным поперечным размером $10 \mu \mathrm{m}$. Вид сигнала на торце контрольного световода соответствует подобным сигналам в случайных процессах без активации. Результаты многократно воспроизводятся в заданных условиях по температуре и давлению. Для указанных условий опытов с н-пентаном при температуре $117^{\circ} \mathrm{C}$ и атмосферном давлении порог активации по интенсивности излучения на длине волны $980 \mathrm{~nm}$ определен на уровне $0.6 \cdot 10^{5} \mathrm{~W} / \mathrm{cm}^{2}$. Значение порога активации зависит от состояния торца световода, а процессы вскипания, вероятно, развиваются на границе раздела сред. Скорость распространения ступенчатого сигнала перед вскипанием, определенная делением рас- стояния между торцами световодов на время задержки между сигналами каналов, составила около $400 \mathrm{~m} / \mathrm{s}$. Это значение существенно отличается от результата измерения скорости звука в перегретом пентане, составившей при заданных условиях $520 \mathrm{~m} / \mathrm{s}$ [10]. По своим свойствам наблюдаемый ступенчатый сигнал отличается от акустических колебаний в жидкости и, возможно, имеет другую природу. Дальнейшее развитие исследований будет направлено на выяснение характерных черт наблюдаемого процесса. В качестве первого шага предполагается постановка опытов при более коротких импульсах лазерного излучения и различных температурах перегрева жидкости.

\section{Финансирование работы}

Исследования поддержаны Российским научным фондом (проект № 19-19-00115).

\section{Конфликт интересов}

Авторы заявляют, что у них нет конфликта интересов.

\section{Список литературы}

[1] Липнягов Е.В., Перминов С.А., Паршакова М.А. // Тепловые процессы в технике. 2018. Т. 10. № 7-8. С. 292-297.

[2] Бусов К.А., Решетников А.В., Мажсейко Н.А., Капитунов O.A. // Прикладная механика и техническая физика. 2019. T. 60. № 1 (353). C. 62-68. DOI: 10.15372/PMTF20190108 
[3] Беликов А.В., Гагарский С.В., Сергеев А.Н., Смирнов С.Н. // Изв. вузов. Приборостроение. 2017. Т. 60. № 4. C. $367-374$.

[4] Буланов А.В., Нагорный И.Г., Соседко Е.В. // Письма в ЖТФ. 2019. Т. 45. В. 23. С. 34-37. DOI: 10.21883/PJTF.2019.23.48717.17586

[5] Чудновский В.М., Юсупов В.И., Дыдыкин А.В., Невожай В.И., Кисилёв А.Ю., Жуков С.А., Баграташвили В.Н. // Квантовая электроника. 2017. Т. 47. № 4. С. 361370.

[6] Starinskiy S.V., Shukhov Y.G., Bulgakov A.V. // Appl. Surf. Sci. 2017. V. 396. P. $1765-1774$

DOI: 10.1016/j.apsusc.2016.11.221

[7] Lipnyagov V.E., Gurashkin A.L., Starostin A.A., Skripov P.V. // J. Eng. Thermophys. 2018. V. 27. N 3. P. 307-318.

DOI: $10.1134 / \mathrm{S} 1810232818030062$

[8] Gurashkin A.L., Starostin A.A., Ermakov G.V., Skripov P.V. // J. Chem. Phys. 2012. V. 136. N 2. P. 021102.

DOI: $10.1063 / 1.3678831$

[9] Гурашкин А.Л., Ямпольский А.Д., Старостин А.А., Скрипов П.В. // Письма в ЖТФ. 2013. Т. 39. В. 16. С. 87-94.

[10] Исмагилов Р.Г., Ермаков Г.В. // ТВТ. 1982. Т. 20. № 4. C. $677-682$. 